\title{
ANALISIS PENGARUH GEOMETRIK DAN KELENGKAPAN RAMBU LALU LINTAS TERHADAP KECELAKAAN (Studi Kasus : Tanjakan Kethekan Kec. Jambu, Ruas Jalan Ambarawa - Magelang Km. 46+000 s/d 46+750)
}

\author{
Rizqi Rangga Perdana ${ }^{1)}$, Yeremia Kristian Adi Permata ${ }^{1)}$, Siti Latifah ${ }^{1, *)}$ \\ Sukoyo ${ }^{1)}$, Wasino ${ }^{1)}$ \\ 1) Jurusan Teknik Sipil Politeknik Negeri Semarang \\ Jl. Prof. Soedarto SH, Tembalang Semarang 50275 Telepon (024) 76480569 \\ ${ }^{*}$ Email: latifahsiti606@gmail.com
}

\begin{abstract}
Ambarawa - Magelang main road is an arterial road which used by drivers who came from Central Java headed to Yogyakarta. The Road Segment is considered to have frequent traffic accidents. The study aims to analyze the relationship between geometric aspects and the occurrence of accidents, compare actual speed with plan speed, and analyzing the completeness of the traffic signs on this section to identify the causes of accidents that occurred at that location. The stages of analysis is by doing the geometric calculation of the road and compared with the requirements in the regulation then identifying whether there is a relationship between accidents that occur with geometric conditions, vehicle speed, and the signs completeness. Identification and results of geometric analysis is known that Black Spot are on bend road I ( $\mathrm{km} \mathrm{46+300)} \mathrm{there} \mathrm{were} 22$ accidents due to breaking road markings, 6 accidents due to extreme bend, and 4 accidents due to road slackness throughout 2012 - 2018. On the bend road II $(\mathrm{km} \mathrm{46+440)}$ there were 5 accidents due to breaking road markings and on the bend road III $(\mathrm{km} \mathrm{46+520)}$ there were 3 accidents due to road slackness. with the result that there is a relationship between geometric conditions with accidents that occur and after being analyzed the completeness of the traffic signs is still lacking and needs to be completed
\end{abstract}

Kata kunci : traffic accidents, geometric, traffic signs

\section{PENDAHULUAN}

Jalan arteri merupakan jalan yang didesain dengan kecepatan rencana yang tinggi dan memiliki perencanaan geometrik yang baik sehingga pengguna jalan dapat dengan cepat, aman, dan nyaman sampai ke daerah tujuan. Salah satu jalan yang memiliki kriteria seperti diatas adalah ruas jalan Ambarawa - Magelang, Kecamatan Jambu (Tanjakan Kethekan) yang merupakan salah satu jalan penghubung kota Ambarawa dengan kota Magelang dan merupakan jalan dengan aksesibilitas yang tinggi dengan kondisi rawan kecelakaan, seperti pada tanggal 8 Juni tahun 2014 terjadi kecelakaan maut yang menimpa dump truck bermuatan pasir yang mengalami rem blong, yang terjadi pada jalan yang menurun, akibatnya dump truck saat itu menabrak 10 kendaraan didepannya hingga menewaskan 5 orang 
pengendara sepeda motor (www.radar semarang.com/ 2014/06/ 16). Kondisi ini didukung oleh banyaknya kecelakaan yang terjadi pada daerah tersebut dalam beberapa tahun sebelumnya. Diantaranya pada tahun 2015 sebanyak 42 kasus kecelakaan, tahun 2016 sebanyak 35 kasus kecelakaan, tahun 2017 sebanyak 11 kasus kecelakaan (Sumber : Satuan Lalu Lintas Kabupaten Semarang). Karena tingkat kecelakaan cukup tinggi maka daerah tersebut menjadi daerah "Black Spot".

Black spot biasanya berkaitan dengan daerah perkotaan dimana lokasi kecelakaan dapat diidentifikasikan dengan pasti dan tetap pada suatu titik tertentu. Keadaan jalan harus sesuai dengan perencanaan yang telah diatur dalam Tata Cara Perencanaan Geometrik Jalan Antar Kota No.038/T/1997. Pentingnya kelengkapan rambu peringatan juga dapat menjadi salah satu faktor yang mempengaruhi angka kecelakaan yang terjadi. Tujuan diberikannya rambu peringatan tersebut yaitu supaya pengemudi berhati-hati dalam menjalankan kendaraannya. Misalnya: rambu yang menunjukkan adanya lintasan kereta api, atau adanya simpangan yang berbahaya bagi para pengemudi. Berdasarkan uraian diatas maka diperlukan kajian mendalam mengenai analisa geometrik dan kelengkapan rambu lalulintas dari jalan Ambarawa - Magelang, Kecamatan Jambu (Tanjakan Kethekan), yang belum pernah dilaksanakan suatu penelitian yang menyangkut kecelakaan, faktor penyebabnya serta solusi pencegahaannya. Penelitian ini dilakukan tidak terlepas dari penelitian - penelitian terdahulu yang pernah dilakukan sebagai bahan perbandingan dan kajian. Adapun hasil - hasil penelitian yang dijadikan perbandingan tidak terlepas dari topik penelitian yaitu : Dalam penelitian Qomaruddin, dkk (2015) telah menganalisa alinyemen horizontal pada tikungan depan Gardu PLN Ngabul di Kabupaten Jepara yang berisi tentang analisa yang dilakukan pada tikungan yang dijadikan sebagai jalan alternatif bagi pengendara dikarenakan jalan utama mengalami kepadatan lalulintas. Wicaksono, dkk (2014) Menganalisa Kecelakaan lalu lintas pada Jalan Raya UngaranBawen yang berisi tentang analisa yang dilakukan di Ruas Jalan tersebut yang merupakan jalan arteri yang pada lalu lintasnya.

Analisa data yang penulis lakukan untuk mengetahui hubungan antar variabel yang berpengaruh terhadap jumlah kecelakaan menggunakan bantuan program komputer SPSS, sedangkan untuk penentuan lokasi rawan kecelakaan (blackspot), menggunakan teknik statistik kontrol lalu lintas. Kejadian kecelakaan lalu lintas disebabkan oleh beberapa faktor, yaitu manusia (pengemudi), lingkungan, kendaraan dan jalan. Dari hasil analisa data, manusia merupakan faktor utama penyebab terjadinya kecelakaan $(66,89 \%)$. Pengemudi yang kurang antisipasi adalah perilaku pengemudi yang paling sering menyebabkan 
terjadinya kecelakaan $(72,45 \%)$. Jenis kecelakaan yang paling sering terjadi adalah tabrak depan depan $(50,85 \%)$, dengan sepeda motor $(53,78 \%)$ sebagai kendaraan yang paling sering terlibat. Waktu yang paling sering terjadi kecelakaan adalah pukul 12.00$18.00 \quad(31,74 \%)$, dan profesi pengemudi yang sering terlibat kecelakaan adalah karyawan / swasta $(61,86 \%)$. Lokasi blackspot di ruas jalan Ungaran Bawen ini ada 6, yaitu Pertigaan Citroen (40 kejadian), Pertigaan Lemah Abang (35) kejadian , Pertigaan Ngobo (31 kejadian), Depan PT Sosro $=(27$ kejadian $)$, Depan PT Apac Inti Corpora (32 kejadian), Pertigaan Bawen (36 kejadian). Fauzan dkk (2016) Mengkaji tentang Geometrik Jalan Raya pada Bundaran Arteri baru Porong Sidoarjo, yang berisi tentang analisa pengaruh bundaran pada simpang Arteri Baru Porong terhadap pergerakan kendaraan yang melewati daerah tersebut.

Metode yang dilakukan yaitu survei /pengukuran topografi pada lokasi studi dengan alat teodolith. Sedangkan penelitian ini akan menganalisis lebih spesifik mengenai keterkaitan antara bentuk geometrik jalan khusunya tikungan dan kelengkapan rambu serta marka jalan dalam prosentase terjadinya kecelakaan.

\section{METODE PENELITIAN}

Metodologi penelitian yang digunakan adalah berupa observasi langsung pada objek lapangan yang akan diteliti. Untuk mendapatkan data yang akurat dan sesuai dengan kondisi lapangan yang sebenarnya dengan menggunakan peralatan penunjang yang akan digunakan. Waktu yang akan digunakan untuk melakukan penelitian ini yaitu: pada minggu ke 11 sampai dengan minggu ke -18 . Tempat dilaksanakannya penelitian ini adalah di jalan Ambarawa - Magelang pada kecamatan Jambu seperti pada Gambar 1 dan di ruas ini akan dilakukan pengukuran pada 3 tikungan pada lokasi tersebut.

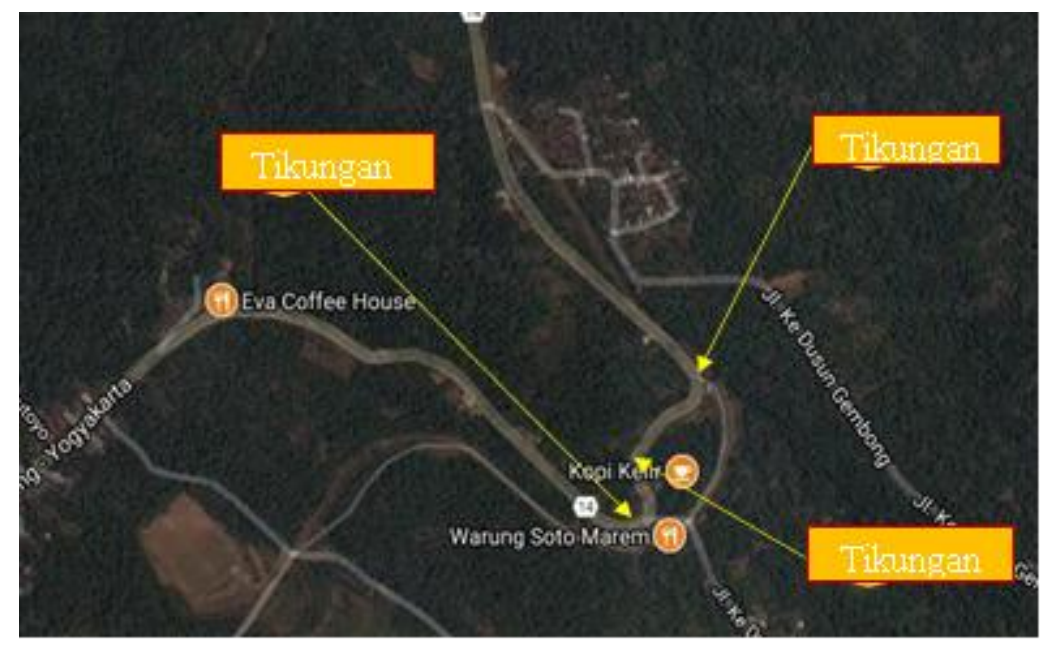

Gambar 1. Lokasi Survei (sumber : Google Map, 2018) 
Data yang dikumpulkan terdiri dari data primer dan data sekunder. Data primer terdiri dari pengamatan rambu lalu lintas yang ada di jalan Raya Ambarawa - Magelang km 46+000 s/d 46+750, pengukuran lebar jalan, pengukuran panjang lengkung pada tikungan, kelandaian jalan, survei kecepatan aktual kendaraan, dan dokumentasi rambu-rambu lalulintas. Sedangkan data sekunder diperoleh dari data - data yang sudah ada sebagai rujukan, antara lain; data kecelakaan lalu lintas yang diperoleh dari Satuan Lalu Lintas Kabupaten Semarang, dan trase jalan yang di peroleh dari Software Google Earth. Pengumpulan data ini dilakukan guna mendapatkan jari - jari tikungan, kelandaian jalan, jarak pandang dan daerah kebebasan samping pada jalan tersebut. Kegiatan yang dilakukan dalam penganalisaan geometrik :

\section{Pengumpulan data}

Data yang perlu didapat yaitu data data yang sudah ada sebagai rujukan, antara lain; data kecelakaan lalu lintas yang diperoleh dari Satuan Lalu Lintas Kabupaten Semarang, dan trase jalan yang di peroleh dari Software Google Earth. Langkah untuk mendapatkan data yang diperlukan untuk perhitungan dan analisa dari geometrik adalah sebagai berikut:

- Menentukan trase jalan dan sudut tikungan sesuai lokasi objek penelitian dengan bantuan software Google Earth

- Menentukan $\Delta$ (sudut tikungan) dari sumber data Google Earth dengan program Autocad

- Menentukan Lc (Panjang tikungan)

- Memperoleh Kelandaian Jalan

Peralatan yang digunakan :

Waterpass, Rambu Ukur,

Rollmeter, Alat Tulis dan Leveling

Field Note.

\section{Analisa Geometrik}

Metode untuk menganalisa geometrik yaitu dengan menghitung data yang sudah didapat dari lapangan ataupun software menggunakan rumus jari jari, rumus jarak pandang dan rumus daerah kebeasan samping yang ada pada TPGJAK No.038/T/1997. Lalu dibandingkan apakah hasil yang didapat memenuhi syarat atau tidak.

\section{Data Kecepatan Aktual Kendaraan}

Survei kecepatan aktual kendaraan dilakukan dengan cara menghitung jarak yang ditempuh kendaraan dibagi dengan waktu. Lokasi survei diambil sepanjang $50 \mathrm{~m}$ pada setiap tikungan. Penganalisaan data kecepatan yang telah dikumpulkan yaitu dengan membuat rata - rata dari data tersebut lalu dibandingkan dengan data kecepatan rencana.

\section{Survei Rambu - Rambu Lalu Lintas dan Marka Jalan}

Analisa ini dilakukan dengan melihat dan mendokumentasi sarana dan fasilitas rambu - rambu lalu lintas yang sudah terpasang dan rambu rambu lalu lintas apa yang belum terpasang di ruas jalan tersebut. Kemudian dianalisa apakah fasilitas tersebut sudah sesuai dengan keadaan 
medan dan memberikan penjelasan tentang rambu lalu lintas yang kurang di ruas jalan tersebut. Semua aspek tersebut disesuaikan pada Peraturan Mentri Perhubungan Republik Indonesia PM Nomor 13 Tahun 2014 Tentang Rambu Lalulintas, PM Nomor 34 Tahun 2014 tentang marka jalan, serta PM Nomor 49 Tahun 2014 tentang alat pemberi isyarat lalu lintas.

\section{HASIL DAN PEMBAHASAN}

Dari hasil pengamatan pada ruas jalan Ambarawa - Magelang tepatnya Jalan Raya Jambu terdapat 3 belokan (tikungan) yang dianggap banyak terjadi gangguan lalu lintas. Berikut pada Tabel 1 merupakan data kecelakaan yang dicatat oleh Satuan Lalulintas Kabupaten Semarang dari tahun $2012-2018$.

Tabel 1. Data Kecelakaan di Jalan Raya Jambu

\begin{tabular}{|l|l|}
\hline Jahun & Jumlah Kecelakaan \\
\hline 2012 & 57 \\
\hline 2013 & 29 \\
\hline 2014 & 25 \\
\hline 2015 & 42 \\
\hline 2016 & 35 \\
\hline 2017 & 11 \\
\hline 2018 (Januari-Februari) & 3 \\
\hline
\end{tabular}

(Sumber: Satuan Lalulintas Kabupaten Semarang)

Berdasarkan analisa yang data yang kemudian dibandingkan dilakukan tentang geometrik, dengan peraturan dari Bina Marga. kecepatan aktual, dan rambu - rambu Ruas jalan Ambarawa - Magelang ini lalu lintas didapatkan hasil yang termasuk ke dalam jalan Arteri Kelas I, nantinya akan dibandingkan dengan ditinjau dari data jalan seperti lebar peraturan - peraturan yang ada. Dari lajur, lebar bahu, median, dan marka perbandingan tersebut maka kita dapat jalan ruas jalan ini memenuhi melihat apakah ketentuan seperti geometrik, kecepatan aktual, dan rambu - rambu lalu lintas tersebut merupakan faktor terjadinya kecelakaan di ruas jalan tersebut atau bukan.

Dari hasil perhitungan persyaratan dari Bina Marga.

a. Alinyemen Horizontal (jari - jari tikungan)

Setelah dilakukan perhitungan Jari-jari minimum dibandingkan dengan jari - jari yang tersedia dalam Tabel 2 sebagai berikut.

geometrik yang ada, didapatkan data- 
Tabel 2. Analisa perbandingan jari - jari minimum dan jari - jari perhitungan

No. Link Sudut Tikungan Panjang Lengkung Jari - jari ( Jari min Keterangan

\begin{tabular}{ccccccc} 
& $\mathrm{Km}$ & $(\Delta)$ & $(\mathrm{LC})$ & $\mathrm{R})$ & $($ Rmin $)$ & \\
\hline & & $\left(^{\circ}\right)$ & $($ meter $)$ & $($ meter $)$ & $($ meter $)$ & \\
\hline 1 & $46+300$ & $95^{\circ} 21^{\prime} 40^{\prime \prime}$ & 70 & 42,05 & 42,58 & Tidak OK \\
2 & $46+440$ & $72^{\circ} 16^{\prime} 39^{\prime \prime}$ & 85 & 67,28 & 49,94 & OK \\
3 & $46+520$ & $132^{\circ} 37^{\prime} 43^{\prime \prime}$ & 102 & 44,06 & 29,75 & OK \\
\hline
\end{tabular}

Dapat diketahui pada tikungan I jari - jari tersebut kurang memenuhi persyaratan jari - jari minimum. Pada Km 46+300 dimana untuk panjang lengkung sebesar $70 \mathrm{~m}$ yang seharusnya memiliki jari - jari minimum sebesar 42,58 $\mathrm{m}$ namun dari jari-jari yang tersedia yaitu $42,05 \mathrm{~m}$. Ukuran jari - jari tersebut masih kurang untuk dapat memenuhi persyaratan jari - jari yang ideal. Hal ini tentunya menjadi salah satu faktor kurang aman dan kurang nyaman bagi kendaraan ketika akan melintas pada tikungan I di $\mathrm{Km} \mathrm{46+300,} \mathrm{sehingga}$ semakin kecil jari-jari suatu tikungan pada jalan semakin tinggi resiko kecelakaan yang akan terjadi.

Suatu peristiwa kecelakaan akibat tikungan tajam di tikungan I terjadi pada tanggal 3 Oktober 2014 yang menimpa sebuah truk dengan nomor polisi B 9171 UEI, berjalan dari Temanggung menuju Ambarawa yang sesampainya di turunan dan tikungan tajam desa Jambu pengemudi tidak bisa mengendalikan kendaraannya sehingga menabrak pagar rumah warga sehingga truk terbalik (Data Lakalantas Tahun 2014).

Sedangkan pada tikungan II di km 46+440 panjang lengkung sebesar 85 meter dimana jari - jari yang tersedia 67,28 meter, lebih besar dari syarat minimumnya yaitu 49,94 meter dan tikungan III di km 46+520 panjang lengkung sebesar 102 meter dimana jari - jari yang tersedia yaitu 44,06 meter, lebih besar dari syarat minimumnya yaitu 29,75 meter. Peristiwa kecelakaan juga kerap terjadi pada tikungan II dan III namun disebabkan oleh faktor yang lain.

b. Kebebasan Samping

Analisa selanjutnya yaitu dari jarak pandang henti dan daerah kebebasan samping didapatkan hasil yaitu seperti pada Tabel 3 .

Tabel 3. Perhitungan Jarak Pandang dan Kebebasan Samping

\begin{tabular}{ccccccc}
\hline \multicolumn{2}{l}{ No. LinkKm Kecepatan Aktual Jari - jari ( R ) } & $\begin{array}{c}\text { Jarak Pandang } \\
\text { (meter) }\end{array}$ & $\begin{array}{c}\text { Kebebasan } \\
\text { (meter) }\end{array}$ & $\begin{array}{c}\text { Kebebasan Samping } \\
\text { yang tersedia }\end{array}$ \\
\hline 1 & $46+300$ & 38 & 42,05 & 36,81 & 3,964 & 2,9 \\
2 & $46+440$ & 41 & 67,28 & 41,6 & 3,19 & 2,5 \\
3 & $46+520$ & 32 & 44,06 & 29,46 & 2,439 & 2,5 \\
\hline
\end{tabular}

Dari data di atas dapat jarak pandang henti yaitu 36,81 meter diketahui bahwa tikungan I km 46+300 dan kebebasan samping seharusnya 
3,964 meter namun dilokasi tersebut pada tikungan I hanya tersedia kebebasan samping dengan lebar 2,9 meter. Hal ini ada kaitannya dengan peristiwa kecelakaan yang terjadi akibat pengendara mendahului dengan kendaraan di depannya hingga melebihi marka jalan yang tidak putus terjadi dari tahun 2012 hingga 2016.

Salah satunya yaitu pada tanggal 1 Januari 2014 terjadi pada jalan raya Ambarawa menuju Secang (Tanjakan Ketekan) Kecamatan Jambu, kendaraan bermotor dengan nomor polisi B 217 AN berjalan dari Secang menuju Ambarawa sesampainya di TKP berjalan terlalu ke kanan hingga melebihi marka jalan tidak putus sehingga sementara itu dari arah berlawanan datang sepeda motor Honda dengan nomor polisi AB 6034 GF karena jarak dekat tidak bisa menghindar maka terjadi laka lantas. (Data Lakalantas Tahun 2014).

Pada tikungan II $\mathrm{km} 46+440$ jarak pandang henti yaitu 41,6 meter dan kebebasan samping seharusnya 3,19 meter namun dilokasi tersebut hanya tersedia 2,5 meter. Kecelakaan akibat mendahului kendaraan hingga melebihi marka terjadi di tikungan II km tanggal 20 Oktober 2015 jalan raya Ambarawa menuju Pringsurat ikut dusun Dedor, kecamatan Jambu sepeda motor dengan nomor polisi H 3102 QI berjalan dari Ambarawa menuju Pringsurat sesampainya di TKP mendahului kendaraan bus dengan nomor polisi tidak dikenal hingga menyerempet bus tersebut dan terjatuh kekanan jalan melebihi AS jalan, sementara itu dari arah berlawanan dating kendaraan bermotor truk $\mathrm{AB}$ 9387 FE karena jarak dekat tidak bisa menghindar maka terjadi laka lantas (Data lakalantas tahun 2015).

Tikungan III km 46+520 jarak pandang henti 29,46 meter dan kebebasan samping seharusnya 2,439 meter pada lokasi tersebut tersedia kebebasan samping dengan lebar 2,5 meter sehingga pada tikungan tersebut terpenuhi kebebasan sampingnya, namun pada lokasi tersebut sempat terjadi kecelakaan akibat melanggar marka.

Oleh karena hal diatas lebar bahu jalan yang ideal tanpa terhalang bangunan ini harus terpenuhi, yang mempunyai fungsi sebagai daerah penyelamat kendaraan yang kehilangan kecepatan ketika menanjak pada jalur tersebut dan juga sebagai jalur untuk mendahului kendaraan di belakang apabila terdapat kendaraan yang mogok atau berjalan lambat di depannya.

c. Kelandaian Jalan

Kelandaian jalan yang telah dihitung dan dianalisa dapat diketahui prosentase kelandaiannya dan dibandingkan dengan peraturan Tata Cara Perencanaan Geometrik Jalan Antar Kota (TPGJAK No.038/TBM/1997) apakah prosentase kelandaian terpenuhi atau tidak. Berikut adalah Tabel 4 yang merupakan hasil perhitungan dan analisa kelandaian jalan. 
Tabel 4. Perhitungan dan Analisa Kelandaian Jalan

\begin{tabular}{cccccc}
\hline No. & \multicolumn{2}{c}{ LinkKm Kecepatan AktualPeraturan TPGJAK } & Kelandaian & Keterangan \\
& & $(\mathrm{km} / \mathrm{jam})$ & Kelandaian $(\%)$ & tersedia $(\%)$ & \\
\hline 1 & $46+310$ & 38 & 10 & 10,35 & Tidak OK \\
2 & $46+420$ & 41 & 9 & 6,125 & OK \\
3 & $46+480$ & 32 & 10 & 11,45 & Tidak OK \\
\hline
\end{tabular}

tikungan I segmen A-B (km $46+310)$ dengan prosentase $10,35 \%$, pada peraturan hanya boleh $10 \%$. Tikungan II Segmen C-D (km 46+420) dengan prosentase $6,13 \%$ dalam peraturan kelandaian maksimum yaitu 9\% sehingga memenuhi syarat. Pada tikungan III segmen EF (km46+480) dengan prosentase kelandaian $11,45 \%$ namun pada peraturan maksimum kelandaian yaitu $10 \%$. Sehingga segmen A-B pada tikungan I dan segmen E-F pada tikungan III tidak memenuhi syarat. Kelandaian suatu jalan harus diperhatikan karena kendaraan berat akan sulit untuk melewatinya dan resiko terganggunya lalu lintas juga pasti akan terjadi. Medan pada ruas jalan Ambarawa -
Magelang tepatnya pada kecamatan Jambu ini termasuk dalam medan perbukitan yang dalam peraturan TPGJAK No.038/TBM/1997 memiliki kemiringan $3 \%-25 \%$.

Hal ini erat kaitannya dengan kecelakaan akibat kelandaian jalan yang terjadi pada 22 September 2012 berada pada tanjakan Ketekan yang melibatkan truk dengan nomor polisi $\mathrm{K}$ 1872 FB yang berjalan dari Jambu menuju Bedono sesampainya di tanjakan kendaraan tidak kuat dan berjalan mundur, sehingga menyebabkan 1 korban. (Data Lakalantas Tahun 2012). Berikut ini Tabel 5 merupakan hasil analisis geometrik yang tidak memenuhi syarat.

Tabel 5. Hasil Analisa Geometrik yang tidak Memenuhi Syarat

\begin{tabular}{ccccll}
\hline No & $\begin{array}{c}\text { Link } \\
\mathrm{km}\end{array}$ & Analisa & Perhitungan & syarat & Keterangan \\
\hline 1 & $46+300$ & Perbandingan Jari-jari & 42,05 & $>42,58$ & TidakMemenuhi \\
2 & $46+300$ & Kebebasan Samping & 2,9 & 3,964 & Tidak Memenuhi \\
3 & $46+440$ & Kebebasan Samping & 2,500 & 3,190 & Tidak Memenuhi \\
4 & $46+310$ & Kelandaian & $10,35 \%$ & $\leq 10 \%$ & TidakMemenuhi \\
5 & $46+480$ & Kelandaian & $11,45 \%$ & $\leq 10 \%$ & TidakMemenuhi \\
\hline
\end{tabular}

d. Analisa Batasan Kritis Tiap beberapa interval kecepatan, kemudian Parameter

Untuk dapat mengetahui batasan kritis didapatkan hasil pada kecepatan tiap parameter dilakukan perhitungan menggunakan rumus di peraturan (TPGJAK 1997) dengan memasukkan manakah yang kritis, seperti pada Tabel 6 yang merupakan batasan kristis parameter geometrik $(\mathrm{km}$ 46+300), serta Tabel 7 pada $\mathrm{km} 46+$ 
440, dan Tabel 8 pada $\mathrm{km} 46+520$.

Tabel 6. Perhitungan Batasan Kritis Parameter Geometrik (km 46+300)

\begin{tabular}{cccccc}
\hline No. & Kecepatan (km/jam) & Jari minimum $(\mathrm{m})$ & Jarak Pandang Henti (m) Kebebasan Samping $(\mathrm{m})$ & Keterangan \\
\hline 1 & 10 & 2,95 & 7,66 & 0,174 & Aman \\
2 & 20 & 11,78 & 16,77 & 0,833 & Aman \\
3 & 30 & 26,51 & 27,32 & 2,200 & Aman \\
4 & 40 & 47,13 & 39,32 & 4,513 & Kritis \\
5 & 50 & 73,64 & 52,77 & 8,011 & Tidak Aman \\
6 & 60 & 106,05 & 67,66 & 12,891 & Tidak Aman \\
\hline
\end{tabular}

Tabel 7. Perhitungan Batasan Kritis Parameter Geometrik (km 46+440)

\begin{tabular}{rccccc}
\hline No. & Kecepatan $(\mathrm{km} /$ jam$)$ & Jari minimum $(\mathrm{m})$ & Jarak Pandang Henti & Kebebasan Samping & Keterangan \\
\hline 1 & 10 & 2,97 & 7,72 & 0,111 & Aman \\
2 & 20 & 11,87 & 17,01 & 0,537 & Aman \\
3 & 30 & 26,70 & 27,86 & 1,437 & Aman \\
4 & 40 & 47,47 & 40,28 & 2,992 & Aman \\
5 & 50 & 74,17 & 54,26 & 5,397 & Kritis \\
6 & 60 & 106,81 & 69,80 & 8,852 & Tidak Aman
\end{tabular}

Tabel 8. Perhitungan Batasan Kritis Parameter Geometrik (km 46+520)

\begin{tabular}{rccccc}
\hline No. & Kecepatan $(\mathrm{km} / \mathrm{jam})$ & Jari minimum $(\mathrm{m})$ & Jarak Pandang Henti & Kebebasan Samping & Keterangan \\
\hline 1 & 10 & 2,90 & 7,65 & 0,166 & Aman \\
2 & 20 & 11,61 & 16,71 & 0,789 & Aman \\
3 & 30 & 26,13 & 27,20 & 2,082 & Aman \\
4 & 40 & 46,45 & 39,10 & 4,267 & Kritis \\
5 & 50 & 72,58 & 52,41 & 7,567 & Tidak Aman \\
6 & 60 & 104,52 & 67,15 & 12,187 & Tidak Aman \\
\hline
\end{tabular}

Dari hasil analisa pada tiap tikungan dan parameter diatas dapat diketahui bahwa pada interval Kecepatan Aktual Kendaraan yang Melintas

kecepatan $10 \mathrm{Km} / \mathrm{jam}$ s/d $30 \mathrm{Km} / \mathrm{jam}$ Data kecepatan aktual kendaraan yang menunjukan kondisi aman. Sedangkan pada interval kecepatan $40 \mathrm{Km} / \mathrm{jam} \mathrm{s} / \mathrm{d}$ telah diperoleh dari Ruas Jalan Ambarawa - Magelang dengan $60 \mathrm{Km} /$ jam, ketiga aspek seperti jari - mengambil sebanyak 20 sampel jari, jarak pandang henti, dan kendaraan dapat diketahui rata-rata kebebasan samping ketiganya kecepatan kendaraan yang melintas menunjukkan kondisi kritis sehingga pada daerah tersebut. Dalam tidak memenuhi persyaratan jalan yang pengambilan data tersebut dibagi aman dan nyaman. menjadi III segmen yaitu pada 
tikungan I (km 46+300), tikungan II (km46+440) dan tikungan III $(\mathrm{km}$ $46+520)$. Rata - rata pada tikungan I yaitu $38 \mathrm{~km} / \mathrm{jam}$, tikungan II yaitu 41 $\mathrm{km} / \mathrm{jam}$, tikungan III yaitu $32 \mathrm{~km} / \mathrm{jam}$. Dengan diketahuinya kecepatan rencana kendaraan yaitu pada tikungan I dengan kecepatan rencana 40 $\mathrm{km} / \mathrm{jam}$, tikungan II yaitu $40 \mathrm{~km} / \mathrm{jam}$, dan tikungan III yaitu $40 \mathrm{~km} / \mathrm{jam}$. Dengan demikian kecepatan kendaraan yang melintas tidak melampaui terlalu jauh dari batas kecepatan rencana. Sehingga kecepatan kendaraan bukan merupakan faktor penyebab kecelakaan pada daerah tersebut.

\section{Rambu - rambu Lalu Lintas dan Marka Jalan}

Pemasangan rambu lalu lintas merupakan fasilitas yang penting bagi pengendara yang hendak melewati jalan tersebut. Setelah dilakukan pengamatan pada ruas jalan tersebut sepanjang 750 meter, terdapat beberapa rambu yang sudah sesuai dengan keadaan medan pada jalan tersebut. Dari pengamatan rambu lalu lintas yang sudah terpasang dapat diketahui bahwa yang digunakan yaitu rambu lalu lintas konvensional sesuai dengan PM No.13 Tahun 2014. Perlu diperhatikan pada rambu yang sudah terpasang dan sesuai dengan keadaan medan jalan tersebut, akan kehilangan fungsinya jika rambu itu terhalang oleh dahan pohon atau rumah warga. Maka dari itu dalam pemasangan rambu perlu diperhatikan letaknya agar mudah dilihat oleh pengendara. Analisa selanjutnya yaitu beberapa rambu yang belum tersedia pada ruas jalan tersebut. Pada km 46+545 pada jalan tersebut terdapat persimpangan yang merupakan akses dari pemukiman warga pada area tersebut belum terdapat rambu peringatan persimpangan tiga sisi. Pada $\mathrm{km}$ $46+555$ terdapat jembatan pada area tersebut namun belum tersedia rambu peringatan adanya jembatan.

Pada km 46+450 pada area tersebut terdapat tikungan ganda ke kiri lalu ke kanan, area tersebut juga belum tersedia rambu peringatan tikungan ganda. Pada km 46+100 adalah area dimana terdapat tanjakan maka perlu diberikan rambu peringatan jalan menanjak dan pengalihan kegigi rendah pada kendaraannya. Pada km 46+545 dibutuhkan lampu isyarat satu aspek warna kuning yang bertujuan agar pengendara lebih meningkatkan kewaspadaannya ketika hendak melintasi area tersebut karena adanya tikungan tajam juga disertai persimpangan pada sisi jalannya. Sepanjang 750 meter jalan Ambarawa - Magelang ini marka jalan yang terdapat pada AS jalan sudah tersedia, namun untuk marka tepi belum terdapat pada ruas tersebut. Marka tepi berfungsi agar pengendara tahu batas tepi dari suatu jalan terutama ketika melintas dimalam hari.

Pada tikungan I dan II belum ada perlengkapan penerangan jalan, hal ini tentu dapat membahayakan pengendara yang melintas pada malam hari karena keterbatasan pandangan, maka perlu diberi penerangan jalan pada tikungan I dan II agar pengendara yang melintas dapat melihat dengan jelas. 
Kurang tersedianya rambu lalu lintas dan marka pada suatu area dapat menjadi salah satu akibat terjadinya kecelakaan di jalan raya, karena rambu dan marka merupakan fasilitas jalan yang sangat vital dan berguna bagi pengendara terutama pengendara yang pertama kali melintas pada jalan tersebut. Terlebih lagi ruas jalan tersebut merupakan jalan nasional yang banyak dilalui kendaraan berat dengan volume yang tinggi. Diagram Hubungan lokasi tikungan dengan jumlah kecelakan yang terjadi pada jalan ambarawa-magelang kecamatan jambu (tanjakan kethekan KM. 46+000 s/d 46+750), seperti pada Gambar 3.

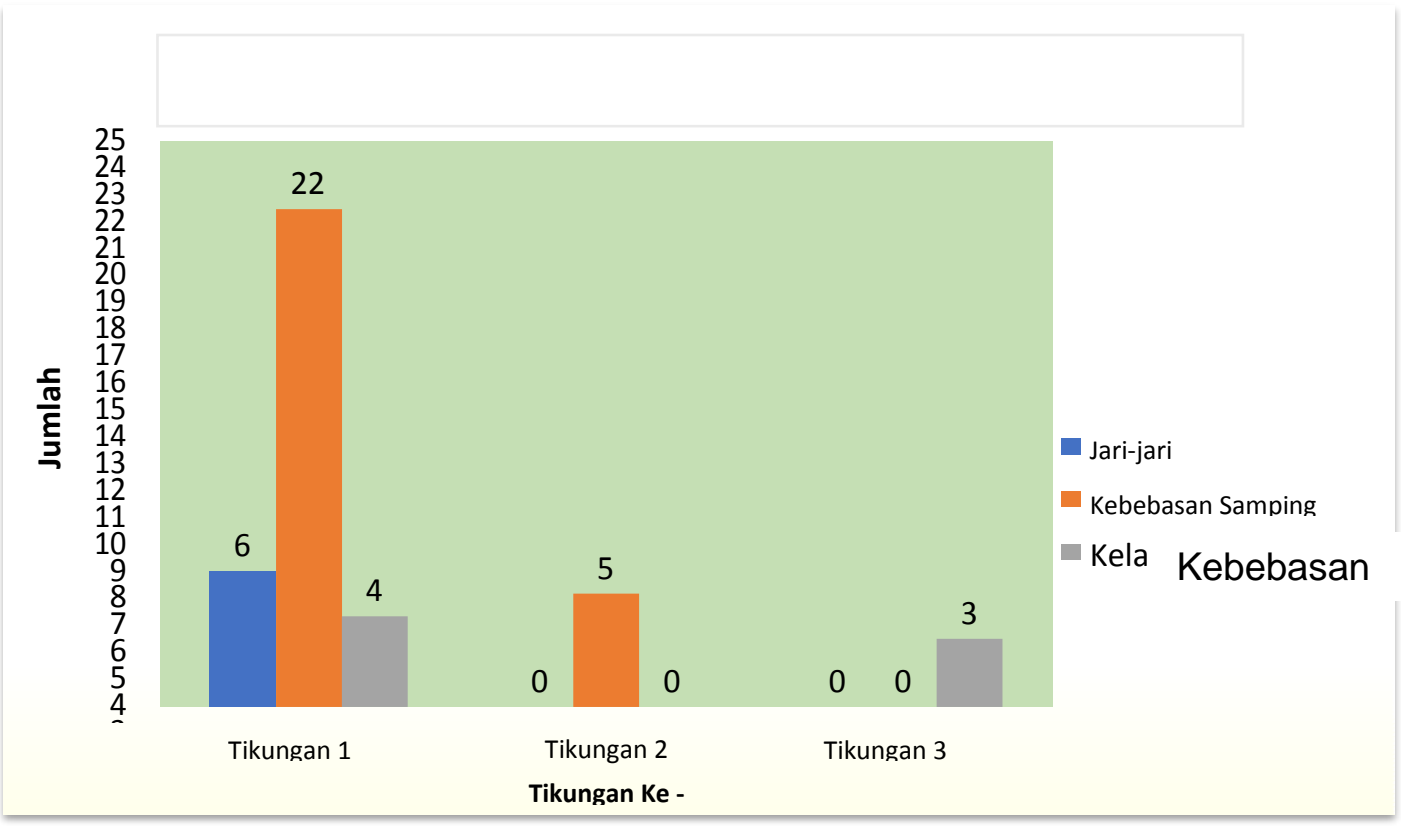

Gambar 3. Hubungan Lokasi Tikungan dengan Jumlah Kecelakaan

\section{SIMPULAN}

Dari hasil analisa geometrik pada ketiga alinyemen horizontal dan pengidentifikasian kecelakaan dapat disimpulkan bahwa jari - jari pada tikungan I yaitu 42,05 m lebih kecil dari jari - jari minimumnya sebesar 42,58 $\mathrm{m}$, kebebasan samping pada lokasi tersebut yaitu 2,9 $\mathrm{m}$ lebih kecil dari perhitungan kebebasan samping selebar 3,964 m, dan kelandaian jalan pada tikungan I yaitu 10,35 \% yang mana kelandaian maksimal seharusnya $10 \%$. Sehingga ketiga aspek geometrik yang telah dianalisa pada tikungan I tidak memenuhi, hal ini dibuktikan dengan peristiwa kecelakaan dari tahun 2012 - 2018 jumlah kecelakaan pada tikungan I akibat jari - jari tikungan sebanyak 6 peristiwa, kebebasan samping 22 peristiwa, dan kelandaian 4 peristiwa.

Jari-jari pada tikungan II yaitu 67,28 m lebih besar dari jari - jari minimumnya sebesar 49,94 m, kebebasan samping pada lokasi tersebut yaitu 2,5 m lebih kecil dari perhitungan kebebasan samping selebar 3,19 m, dan kelandaian jalan pada tikungan II yaitu $6,125 \%$ tidak 
melebihi kelandaian maksimal sebesar $9 \%$. Sehingga ada 1 aspek geometrik pada tikungan II yang tidak memenuhi yaitu kebebasan samping. hal ini dibuktikan dengan peristiwa kecelakaan dari tahun 2012 - 2018 jumlah kecelakaan pada Tikungan II akibat kebebasan samping sebanyak 5 peristiwa.

Jari-jari pada tikungan III yaitu 44,06 m lebih besar dari jari - jari minimumnya sebesar 29,75 m, kebebasan samping pada lokasi tersebut yaitu 2,5 m lebih besar dari perhitungan kebebasan samping selebar 2,439 m, dan kelandaian jalan pada tikungan III yaitu $11,45 \%$ yang mana kelandaian maksimal seharusnya $10 \%$. Sehingga ada 1 aspek geometrik pada tikungan III yang tidak memenuhi yaitu kelandaian. hal ini dibuktikan dengan peristiwa kecelakaandari tahun 2012 - 2018 jumlah kecelakaan pada Tikungan III akibat kelandaian sebanyak 3 peristiwa. Kecepatan kendaraan yang melintas tidak melampaui terlalu jauh dari batas kecepatan rencana. Hal ini menunjukan tidak ada hubungan yang signifikan antara kecepatan kendaraan dengan tingkat kecelakaan di ruas jalan tersebut.

Dari hasil pengamatan ramburambu lalu lintas dan marka jalan sepanjang 750 meter sudah ada 9 rambu yang tepat terpasang, namun juga terdapat 5 rambu dan marka yang kurang yaitu rambu peringatan persimpangan tiga sisi $(\mathrm{km} 46+545)$, rambu peringatan adanya jembatan (km 46+555), rambu peringatan

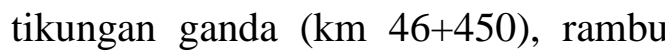

peringatan adanya tanjakan (km 46+100), lampu isyarat satu aspek warna kuning sebagai peringatan untuk hati - hati $(\mathrm{km} \mathrm{46+545)} \mathrm{dan} \mathrm{marka} \mathrm{tepi}$ sepanjang 750 meter. serta pada Tikungan I dan II belum terdapat perlengkapan penerangan jalan. Sehingga disimpulkan bahwa pada ruas jalan tersebut kurang rambu lalu lintas dan marka tepi serta penerangan jalan.

\section{DAFTAR PUSTAKA}

Data Lakalantas Kabupaten Semarang. (2012-2018). www.satlantassemarang.com.

Direktorat Jenderal Bina Marga, 1997, Tata Cara Perencanaan Geometrik Jalan Antar Kota, No.038/T/1997. Badan Penerbit Pekerjaan Umum, Jakarta.

Fauzan E. R, Thoriq Y. A, Arif M. Z, Wicaksono A, 2016, Kajian Geometrik Jalan Raya Pada Bundaran Arteri Baru Porong Sidoarjo. Jurnal Mahasiswa Jurusan Teknik Sipil : Volume 2, Nomor 2, Halaman 45 - 57. Google Inc., 2018, Google Maps: Peta Lokasi Jalan Ambarawa Magelang Kecamatan Jambu dalam http://maps.google.com/

Kementeri Perhubungan Republik Indonesia, 2014, Peraturan Menteri Perhubungan Republik Indonesia Nomor 13 Tahun 2014 Tentang Rambu Lalu Lintas. Jakarta.

Kementrian Perhubungan Republik Indonesia, 2014, Peraturan Menteri Perhubungan Republik Indonesia Nomor 34 Tahun 2014 Tentang Marka 
Jalan. Jakarta.

Kementrian Perhubungan Republik Indonesia, 2014, Peraturan Mentri Perhubungan Republik Indonesia Nomor 49 Tahun 2014 Tentang Alat Pemberi Isyarat Lalu Lintas, Jakarta

Qomaruddin, Sudarno, Saputro A. S,

2016, Analisis Alinyemen Horizontal Pada Tikungan Depan Gardu PLN Ngabul di Kabupaten Jepara. Jurnal Disprotek: Volume 7, Nomor 2, Halaman $36-42$.
Radar Semarang, 2014, Tanjakan Kethekan Paling Banyak MintaTumbal.

www.radarsemarang.com/2014 /06/16/tanjakan-kethekanpaling-banyak-minta-tumbal/ Wicaksono Y. I, Wicaksono D, Fathurochman R. A, Riyanto B., 2014, Analisis Kecelakaan Lalulintas (Jalan Raya Ungaran - Bawen). Jurnal Karya Teknik Sipil : Volume 3, Nomor 2, Halaman 345355 . 